\title{
Book review. Péter Érdi: Ranking一the unwritten rules of the social game we all play
}

\section{Oxford University Press, Oxford, 2020, ISBN: 978-0-19-093,546-7}

\author{
Gábor Lente $^{1}$ \\ Published online: 31 January 2020 \\ (c) Akadémiai Kiadó, Budapest, Hungary 2020
}

When I write this book review, 4 weeks have passed since I received the 2018 Publisher's report on the performance of Reaction Kinetics, Mechanisms and Catalysis in the form of a Powerpoint presentation. Amidst a bunch of confidential data, there is also some public information there: based on the impact factor, RKMC ranks as No. 118 out of 148 in the category 'Chemistry, Physical', and the SCImago journal rank of the title was 0.374 in 2018 (now word about the SCImago of competitor journals in the report). The word 'rank' appears in the document 14 times even though it mostly contains figures and tables. From this, otherwise highly objective collection of facts, it is obvious that we humans are fascinated (or sometimes perhaps even obsessed) with ranking and comparison.

This is why Peter Érdi's recent, science-based, but still highly personal book titled Ranking [1] is a must-read to everyone who wishes to avoid being overly depressed by some unfavorable ranking result. First, a bit of humor always helps accept harsh reality. Second, and much more important, the reader will certainly sharpen her or his skills to find specific reasons in any ranking system to prove that the methodology leading to the unwelcome final result is totally unjust. And finally, the book helps develop an increased tolerance toward the fact that the unjust ranking methods are still widely used to aid decision making.

The author has deeper connections to the scientific field of the journal Reaction Kinetics, Mechanisms and Catalysis than the title seems to imply. Péter Érdi is introduced as a computational scientist by Scott E. Page in the foreword of the book, but he graduated as a chemist in Hungary. Today, he rather unevenly shares his time between Kalamazoo College in Michigan, USA and the Wigner Research Center of Physics (formerly of the Hungarian Academy of Sciences) in Budapest, Hungary. His research background occasionally surfaces in the book as well. For example, in the Epilogue (Chapter 9), which is a particularly personal part of the

Gábor Lente

reac@gamma.ttk.pte.hu

1 Reaction Kinetics, Mechanisms and Catalysis, Department of General and Physical Chemistry, University of Pécs, Pecs, Hungary 
text, Péter gives several reasons why he does not have a Hirsch index similar to a scientific star's. One of the points is this:

Second, my mathematician friend (the one who never had a car) and I discovered/constructed an algorithm (for stochastic simulation of chemical reactions), but we did not have the ideas and the resources to publish properly. The same algorithm was published by an American scientist who worked for the Naval Weapons Center in China Lake, California, maybe a year later, and the papers generated 20,000-plus citations. (Sour grapes, I know.).

As I often work with stochastic kinetics, this story is not totally unfamiliar to me, and possibly many other experts will also recognize that this section refers to the Gillespie algorithm [2]. Péter Érdi and János Tóth introduced this method in Hungarian publications (I do not only mean the country of origin, but also the language here), which is not a good strategy to impress the scientific world, but the story also involves at least two papers in English [3, 4], which still pre-date the work of Gillespie. They were published in the very first volume of an international journal co-founded by the Soviet and Hungarian Academies of Science, which is still running today under the name Reaction Kinetics, Mechanisms, and Catalysis. The Editor-in-Chief dreams of publishing papers with similar potential impact today and is fully determined not to let them be lost in the endless ocean of routine scientific literature.

Another reason for the less-than-star-quality Hirsch index in the epilogue reads:

Fourth, I have spent years writing monographs for books in Hungarian instead of working on scientometrically more efficient papers.

Actually, Péter Érdi also happened to co-author a book with his mathematician friend János (the one who never had a car) in English on the mathematical models used in chemical kinetics [5], but this one was not entirely inefficient scientometrically (594 citations in Google Scholar in January 2020). In addition, he also co-authored a widely cited volume on neural organization [6], wrote a book on complexity [7], and also managed to convince me to co-operate on a short monograph on stochastic chemical kinetics a few years ago [8].

With this diverse scientific background, aptitude for self-reflection and sharpness of social observation, it should surprise no-one that Ranking is a hilarious read. There are seven full chapters between the Prologue and Epilogue, each of which is closed by a very short 'lessons learned' section with notes, mostly containing literature references, conveniently placed at the end of the book. I was left with the feeling that the main stories mostly revolve around sports, education and scientific research, but I realize this fact probably reflects my own preferences and not the author's. Fans of music, English literature, economy, game theory or network science will probably also find some highly original remarks in the book.

In this review, I do not wish to spoil the fun of those who decide to read Ranking by giving away some of the content-except in a single example. Péter 
acutely points out that (almost) all Hungarian males have a strong emotional reaction to soccer (call it football if you happen to live in Europe). Soccer gives a huge playing field for both ranking and ranking injustice. In January 2020, the official FIFA Coca Cola World men's ranking is topped by a national team that has never won a major tournament (in fact, never even made it to a final). It may be a surprise to today's fans that individual player performance was numerically evaluated well before the introduction of InStat. The second figure in the book shows the ranking of right backs on their seasonal scores in the Hungarian soccer league in 1967, given by the (subjective) evaluation of journalists and later averaged (objectively). So far so good, a funny attempt made to calculate an objective measure from admittedly subjective starting data. However, why right backs and why 1967? Péter's mathematician friend (the one who never had a car), on my request, guessed that the specific selection of right backs and the year was because this particular list was topped by a player from the favorite team of the author.

A book like this should be made easily available for a wide readership. I was really happy to learn that there is already interest in German and Chinese translations. Hopefully, there will be a Hungarian edition as well. At this point, the reader should urgently stop perusing my opinion and open Péter's book.

\section{References}

1. Érdi P (2020) Ranking. Oxford University Press, New York

2. Gillespie DT (1976) A general method for numerically simulating the stochastic time evolution of coupled chemical reactions. J Comput Phys 22:403-434

3. Sipos T, Tóth J, Érdi P (1974) Stochastic simulation of complex chemical reactions by digital computer. I. The model. React Kinet Catal Lett 1:113-117

4. Sipos T, Tóth J, Érdi P (1974) Stochastic simulation of complex chemical reactions by digital computer. II. Applications. React Kinet Catal Lett 1:209-213

5. Érdi P, Tóth J (1989) Mathematical models of chemical reactions. Theory and applications of deterministic and stochastic models. Manchester University Press, Princeton

6. Arbib MA, Érdi P, Szentágothai J (1997) Neural organization: structure, function dynamics. MIT Press, Cambridge

7. Érdi P (2008) Complexity explained. Springer, Berlin

8. Érdi P, Lente G (2014) Stochastic chemical kinetics. Theory and (mostly) systems biological applications. Springer, New York

Publisher's Note Springer Nature remains neutral with regard to jurisdictional claims in published maps and institutional affiliations. 